\title{
Synthesis of porous silica with hierarchical structure directed by a silica precursor carrying a pore-generating cage $\dagger$
}

\author{
Whirang Cho, ${ }^{a}$ Bong Jun Cha, ${ }^{a}$ Hyung Ik Lee, ${ }^{b}$ Ji Man Kim ${ }^{b}$ and Kookheon Char ${ }^{* a}$ \\ Received 17th June 2008, Accepted 7th August 2008 \\ First published as an Advance Article on the web 18th September 2008 \\ DOI: 10.1039/b810295c
}

We have obtained a new class of porous silica with good structural order and additional corrugated nanopores clustered around the primary mesopores from the co-condensation of TEOS and adamantylphenol-grafted trimethoxysilane (adam-graft SQ) using a triblock Pluronic P123 $\left(\mathrm{EO}_{20} \mathrm{PO}_{70} \mathrm{EO}_{20}, M_{\mathrm{w}}=5800\right)$ copolymer as a structure-directing agent. Thermally activated removal of pore-generating moieties (i.e., adamantylphenol groups) in adam-graft SQ involves the generation of secondary micro-to-small mesopores, while the block copolymer template generates 2D-hexagonal mesopores. We found that the mesostructural characteristics and the generation of secondary indented pores right next to the mesopores can be tailored by the addition order of the two silica precursors (TEOS and adam-graft SQ), varying the molar ratio between TEOS and adam-graft SQ in the starting sol mixture, and the degree of silica polymerization. The increase in the hexagonal unit cell parameters is attributed to the increment of pore size originating from the removal of adamantylphenol moieties. It is believed that the hydrophobicity of adamantylphenol groups plays a key role in its selective incorporation into the region near the PPO core blocks and the subsequent generation of corrugated pores along the silica channels resulting in the increase of pore diameter.

\section{Introduction}

Mesoscopically ordered silicas have recently generated tremendous research interest for potential applications in catalysis, adsorbents, biomineralization and advanced materials design, due to the well-defined structural order, high surface area, and large pore volume. ${ }^{1-4}$ Most recently, well-defined hierarchical or multimodal porous materials have attracted much attention owing to the technological promise in applications based on combining the fast accessibility of functional molecules through large pores with the high surface area and better selectivity with smaller pores. Several attempts to synthesize mesostructured silica with bimodal pore size distribution (PSD) combining macro-meso, macro-micro, or meso-micropores have been reported since 1998. ${ }^{5,6}$ In general, physical templating methods based on PS latex spheres have extensively been explored as an efficient route to generate large macropores, ${ }^{7}$ while templates with smaller feature size were also employed to generate meso- to micropores. However, some physical template techniques may not be easy or economical for eventual scaling-up of the process (because of, for example, long sedimentation time), so that the development of an alternative chemical templating method is required that could generate both micro- and meso-scale pores in a controlled and efficient way. ${ }^{8}$

${ }^{a}$ School of Chemical and Biological Engineering, Center for Functional Polymer Thin Films, Seoul National University, San 56-1, Shillim-dong, Kwanak-gu, Seoul, 151-744, Korea. E-mail: khchar@plaza.snu.ac.kr; Fax: +82-2-873-1548; Tel: +82-2-880-7431

${ }^{b}$ Department of Chemistry, Sungkyunkwan University, Chunchun-dong, Jangan-gu, Suwon, 440-746, Korea

$\uparrow$ Electronic supplementary information (ESI) available: Table S1; Fig. S1 and S2. See DOI: 10.1039/b810295c
The realization of small meso- or micropores within the amorphous walls of porous silica materials containing primary mesopores offering specific functions such as improved diffusion rate, immobilization capability, the controlled release of reactant molecules and so forth would generate advantages, because molecules can be readily transported through the mesochannels and can subsequently be adsorbed onto the micropores located near the silica walls without too much difficulty. ${ }^{9,10}$ As a result, the simultaneous or hierarchical generation of micro or small mesopores near the silica walls with controlled pore size and topology is quite important and attractive for the design of novel porous materials retaining regular mesostructured pores for further applications.

While several research groups have previously suggested the presence of microporosity within the mesoporous walls in SBA-15 and MCM-41, ${ }^{10-13}$ a systematic way of controlling the size and size distribution of micropores as well as the pore volume is still challenging. The use of two templating agents has been widely employed in achieving hierarchical porous structures. These synthetic approaches, however, generally resulted in no or slight regular mesopore arrangements. According to the recent work demonstrated by Ryoo and co-workers, amphiphilic organosilanes have proven to be effective structure-directing agents for the synthesis of mesoporous zeolites with tunable mesoporous structure, while avoiding the possible phase separation problem frequently observed when two different templating agents were used. ${ }^{14}$

In present study, we propose a new synthetic strategy utilizing adamantylphenol pore-generating moieties covalently bonded to trialkoxysilyl groups, which could generate secondary (micro- or small meso-) pores within the silica framework. To the best of our knowledge, this is the first report that hierarchically ordered 
porous silica, retaining long-range hexagonal order with smaller pores at the inner mesowalls, can be prepared through the co-condensation of TEOS and adamantylphenol-grafted trimethoxysilane (referred to as adam-graft SQ) in the presence of an amphiphilic triblock copolymer, Pluronic P123 $\left(\mathrm{EO}_{20} \mathrm{PO}_{70} \mathrm{EO}_{20}\right.$, $\left.M_{\mathrm{w}}=5800\right)$ as a structure-directing agent. This approach for the synthesis of porous silica with multiple length scales offers the opportunity to control pore topology as well as its location within the silica framework. In addition, the presence of organic groups within the silica framework by co-condensation of two different types of silica precursors could yield materials with a number of favorable properties such as hydrophobicity, multifunctionality, and structural rigidity. ${ }^{15}$

\section{Experimental}

\section{Preparation of porous silica with structural variation}

A detailed synthetic procedure for the preparation of (3-[(4-adamantan-1-yl-phenoxy)propyl]trimethoxysilane; adamgraft SQ) containing the adamantylphenol group as a poregenerating moiety, linked to the silsesquioxane matrix through a chemical linker, has previously been reported. ${ }^{16,17}$ The synthesis of mesoporous silica, SBA-15, was performed following the wellestablished procedures based on P123 block copolymer templates as described in the literature. ${ }^{18,19}$ The reference mesoporous silica without adam-graft SQ is denoted T10 (T stands for TEOS). In the synthesis of porous silica with structural variation, both TEOS and adam-graft SQ were used as silica precursors with Pluronic P123 $\left(\mathrm{EO}_{20} \mathrm{PO}_{70} \mathrm{EO}_{20}, M_{\mathrm{w}}=5800 ; \mathrm{BASF}\right)$ as a block copolymer template. In a typical synthetic procedure, $1 \mathrm{~g}$ of P123 was dissolved in $1.5 \mathrm{M} \mathrm{HCl}$ aqueous solution containing $36.5 \mathrm{~g}$ of water, and varying amounts of adam-graft SQ precursor and TEOS were sequentially added to the homogeneous solution. The molar composition of this sol is $x$ TEOS : $0.02 \mathrm{P} 123$ : $y$ adam-graft SQ precursor : $6.45 \mathrm{HCl}: 210.7 \mathrm{H}_{2} \mathrm{O}$ (where $x=1$, $0.97,0.94$ and 0.9 , and $y=0.14,0.19,0.24$ and 0.3 , respectively). After stirring the mixture for $1 \mathrm{~h}$ at $298 \mathrm{~K}$, the solid products were then successively aged at $298 \mathrm{~K}$ for $24 \mathrm{~h}$, and then at $368 \mathrm{~K}$ for $24 \mathrm{~h}$. To study the influence of the different extent of silica condensation on the structural characteristics of porous silica, the organosilicate samples were aged at $368 \mathrm{~K}$ for $1-3$ days. The resulting precipitates were then filtered, recovered by washing repeatedly with distilled water, and then dried in a convection oven for $24 \mathrm{~h}$. The removal of the block copolymer template and the pore-generating adamantylphenol moieties, embedded in the silica framework, was carried out by calcination at $450{ }^{\circ} \mathrm{C}$ for $1 \mathrm{~h}$ in a furnace under $\mathrm{N}_{2}$ purge. The resulting silica samples are denoted as Txg1. (where $x$ denotes the relative molar ratio of TEOS with respect to the adam-graft SQ and $g$ is the abbreviation for adam-graft SQ)

\section{Sample characterization}

Powder SAXS experiments were performed at the 4C1 Beamline of Pohang Light Source using a synchrotron radiation with $\lambda=$ $1.54 \AA$ A. Data obtained with a 2D detector were processed by a 2D data processing software. $\mathrm{N}_{2}$ adsorption-desorption isotherms were measured with a Micromeritics ASAP 2010 analyzer. All of the samples were degassed at $423 \mathrm{~K}$ and $30 \mathrm{mT}$ Torr for $4 \mathrm{~h}$ and the pore size distribution was calculated from the adsorption branch of an isotherm by the BJH method. TEM images were obtained with a JEM-3010 instrument at an accelerating voltage of $300 \mathrm{kV}$. Samples were sonicated for $0.5 \mathrm{~h}$ in ethanol and the suspensions were loaded onto carbon films placed over copper grids. ${ }^{29} \mathrm{Si}$ CP-MAS NMR spectra were obtained using a AVANCE $400 \mathrm{WB}$ spectrometer (model DSX-400) at $7 \mathrm{kHz}$, and FT-IR spectra were obtained with a JASCO FT/IR 200 spectrometer.

\section{Results and discussion}

We have recently designed and synthesized a new class of organosilicates (silsesquioxane (SQ)) containing a pore-generating carbon cage linked to SQ, and one example is 1-(4-trimethoxysilylpropoxyphenyl)adamantane (adam-graft $\mathrm{SQ}$ ). ${ }^{16,17}$ The adamantylphenol moiety grafted onto the SQ was utilized as a molecular template, generating secondary small pores along with primary mesopores templated by the P123 block copolymer.

Fig. 1 shows the small angle X-ray scattering (SAXS) patterns for both $\mathrm{T} 10$ and $\mathrm{T} 5 \mathrm{~g} 1$ samples. The T10 sample represents the typical three well-resolved peaks corresponding to (100), (110) and (200) reflections, characteristic of the p6mn 2-D hexagonal symmetry. ${ }^{18,20}$ The intense (100) peak shows the lattice spacing of $d=9.7 \mathrm{~nm}$ corresponding to the 2D-hexagonal unit cell parameter $a=11.2 \mathrm{~nm}$. Interestingly, when the adam-graft SQ is added to the silica sol mixture, the p6mn hexagonal mesoscopic order is still preserved, as shown in Fig. 1(B). However, the (100) peak is slightly shifted to a lower Bragg angle with a lattice spacing $d=11.8 \mathrm{~nm}$ corresponding to the 2D-hexagonal unit cell parameter $a=13.6 \mathrm{~nm}$, which is larger than that of the T10 sample. A well-defined 2D hexagonal structure such as the SBA-15 type material (Fig. 1(A)) is only obtained when the adam-graft SQ is first reacted, and then TEOS introduced to

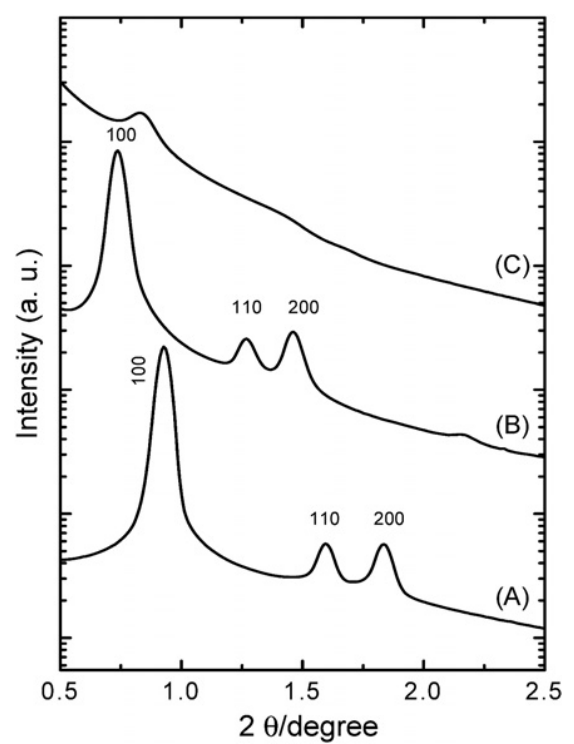

Fig. 1 Small angle $X$-ray scattering patterns of calcined porous silicas prepared with: (A) TEOS only (T10); (B) adam-graft SQ introduced first followed by the addition of TEOS; (C) a mixture of TEOS and adamgrafted SQ added simultaneously. 
the silica sol mixture, as shown in Fig. 1(B). This charge sequence in silica source allows the hydrophobic adamantylphenol groups to preferentially occupy the reaction sites adjacent to the PPO core block, around which silica moieties of adam-graft SQ react with the EO block through a $\left(\mathrm{S}^{0} \mathrm{H}^{+}\right)\left(\mathrm{X}^{-} \mathrm{I}^{+}\right)$pathway under acidic conditions. ${ }^{21,22}$ Cooperative condensation to $\mathrm{SiO}_{2}$ in the presence of the block copolymer template continues as TEOS is continuously incorporated into the assembly of adam-graft SQ/block copolymer composites. In contrast, when a mixture of TEOS and adam-graft SQ is simultaneously added, different hydrolysis and condensation rates between the two different types of silica species makes two different templating systems work in a competitive (rather than a cooperative) way, resulting in the disordered mesostructure (see Fig. 1(C)). The morphological distinction of calcined particulates, which varied upon the addition order of silica precursors, can also be reliable evidence for confirming regular pore alignment. (see Fig. S1†).

Fig. 2(a) and 2(b) represent the $\mathrm{N}_{2}$ adsorption-desorption isotherms and corresponding $\mathrm{BJH}$ pore size distributions, respectively, of these silica samples with different adam-graft
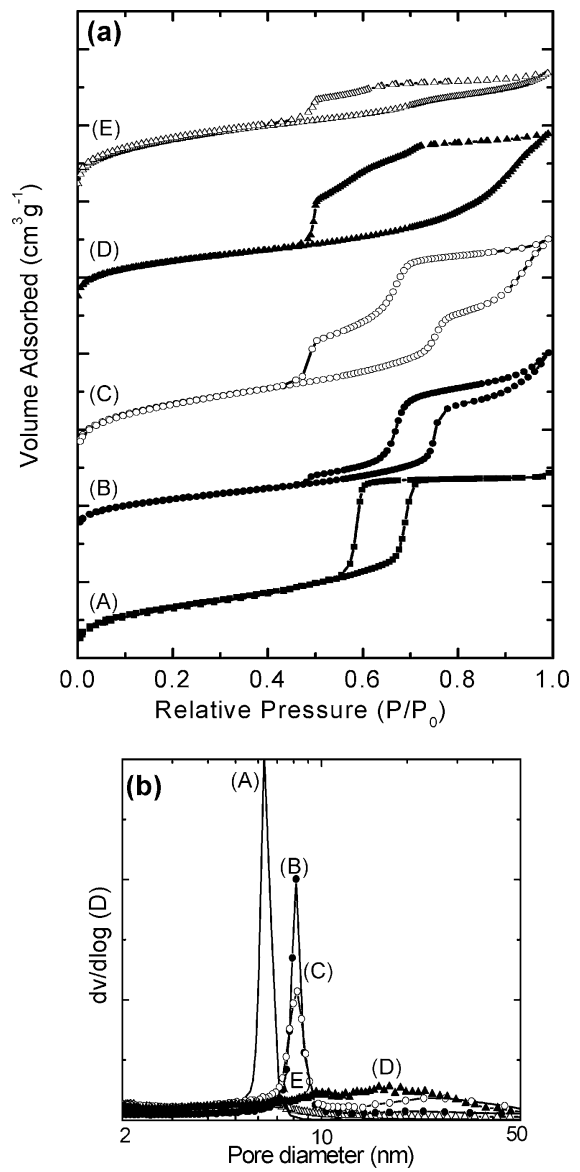

Fig. 2 (a) $\mathrm{N}_{2}$ adsorption-desorption isotherms for porous silicas synthesized by varying the molar ratios between TEOS and adam-graft SQ in the presence of a triblock Pluronic P123 (EO20PO70EO20: $M_{\mathrm{w}}=$ 5800) template: (A) T10; (B) T7g1; (C) T5g1; (D) T4g1; (E) T3g1 (the isotherms for samples B, C, D and E were vertically shifted by 300,500 , $900,1100 \mathrm{~cm}^{3} \mathrm{~g}^{-1} \mathrm{STP}$, respectively, for clarity). (b) Corresponding pore size distribution curves. Pore size distribution curves were calculated from adsorption branches using the BJH method.
SQ contents. The isotherm of T10 sample (Fig. 2(a) (A)) is Type IV with a H1 hysteresis loop, characteristic of SBA15-type mesoporous material, while the isotherms of $\mathrm{T} 7 \mathrm{~g} 1$ and T5g1 exhibit two inflections. The first inflection in the isotherm $\left(0.7<P / P_{0}<0.8\right)$ is shifted to a higher relative pressure compared with the inflection of T10 sample. In the corresponding pore size distribution curve shown in Fig. 2(b), the mean pore size is around $8.3 \mathrm{~nm}$, which is considerably higher compared to the pore diameter of $6.2 \mathrm{~nm}$ for T10. The desorption isotherm of the T7g1 sample (Fig. 2(a) (B)) shows pronounced tailing, while the T5g1 sample (Fig. 2(a) (C)) shows a widening hysteresis loop and an abrupt decline in the desorption tail at $0.4<P / P_{0}<$ 0.45 , corresponding to the lower limit of hysteresis for nitrogen at $77 \mathrm{~K}^{23-26}$ These observations have been attributed either to small pores connected between neighboring mesopores or to the constriction in mesopore channels., ${ }^{96-28}$

The first introduction of adam-graft SQ, followed by the addition of TEOS, should result in indented pores within the mesochannels, and a subsequent increase in pore size. This hypothesis leads us to believe that the desorption trace of both $\mathrm{T} 7 \mathrm{~g} 1$ and $\mathrm{T} 5 \mathrm{~g} 1$ is a consequence of corrugated pore channels due to the pitted pores around mesochannels. It is expected that as more adamantylphenol groups are incorporated near the PO core block, the degree of wrinkled structure along the inside silica walls is more pronounced. This indicates that the formation of small pores along the silica walls in the T5g1 sample is significant when compared with the $\mathrm{T} 7 \mathrm{~g} 1$ sample, representing a decrease in the uniformity of diameter along the pore channels. ${ }^{26,29,30}$ In addition to the narrow distribution of primary corrugated mesopores, the porous silica samples containing the adam-graft SQ exhibit a wide range of small meso- and micropores with a broad maximum around $2 \mathrm{~nm}$. The presence of micropores is also evident from the increase of $V_{\text {micro }}$ (micropore volume) with the increase in adam-graft SQ content up to T4g1 (Table 1). ${ }^{31}$

The second inflection observed for $\mathrm{T} 7 \mathrm{~g} 1$ and $\mathrm{T} 5 \mathrm{~g} 1$ samples at $P / P_{0}>0.8$ can be attributed to the adsorption into larger pores that are either located inside the particulate (intraparticle pores) ${ }^{4}$ or arising from textural pores (interparticle pores). ${ }^{32-35}$ Taking into account the thinned silica walls by the corrugated pores, the larger mesopores could be interconnected one another through the silica walls, causing the open hysteresis in isotherms at $P / P_{\mathrm{o}}>$ 0.8. The pore size distribution profile on T5g1, shown in Fig. 2(b), shows another weak and broad peak around $30 \mathrm{~nm}$, implying that the interconnected mesopores are much less probable when compared with the corrugated mesopores centered at $8.3 \mathrm{~nm}$. The effect of the amount of adam-graft SQ on the mesostructural order has also been examined by SAXS (see Fig. S2 $\dagger$ ), showing that the hydrophobic adamantylphenol groups can be incorporated into the region close to the PPO core blocks up to $\mathrm{T} 5 \mathrm{~g} 1$ while retaining the structural order. Upon further increasing the adam-graft SQ content, a disordered pore structure was obtained, representing the soldered small particle aggregates ${ }^{36}$ in the case of $\mathrm{T} 4 \mathrm{~g} 1$ and $\mathrm{T} 3 \mathrm{~g} 1$ samples (see also Fig. S2†). Consequently, the open hysteresis loop in the $\mathrm{N}_{2}$ isotherm might be attributed to the interparticle pores for T4g1 and T3g1. Furthermore, the pore size distribution of both T4g1 (Fig. 2(a) (D)) and T3g1 (Fig. 2(a) (E)) becomes much broader and shifts to the larger pore size due to the lack of structural order (see Fig. S2 $\dagger$ ) by the aggregation of adamantylphenol groups. 
Table 1 Physicochemical properties of different types of porous silicas obtained from $\mathrm{N}_{2}$ adsorption-desorption isotherms

\begin{tabular}{|c|c|c|c|c|c|c|}
\hline $\begin{array}{l}\text { Sample } \\
\text { code }\end{array}$ & $\begin{array}{l}\text { Surface } \\
\text { area }^{a} / \mathrm{m}^{2} \mathrm{~g}^{-1}\end{array}$ & $\begin{array}{l}\text { Pore } \\
\left.\text { volume } \mathrm{e}^{b} / \mathrm{cm}^{3} \mathrm{~g}^{-1}\right)\end{array}$ & $\begin{array}{l}\text { Micropore } \\
\text { volume } / \mathrm{cm}^{3} \mathrm{~g}^{-1}\end{array}$ & $\begin{array}{l}\text { Pore } \\
\text { diameter } / \mathrm{nm}\end{array}$ & $\begin{array}{l}\text { Unit cell } \\
\text { parameter }{ }^{e} / \mathrm{nm}\end{array}$ & $\begin{array}{l}\text { Wall } \\
\text { thickness } / \mathrm{nm}\end{array}$ \\
\hline $\mathrm{T} 7 \mathrm{~g} 1$ & 560 & 0.78 & 0.0069 & 8.2 & 13.2 & 5 \\
\hline $\mathrm{T} 4 \mathrm{~g} 1$ & 670 & 0.86 & 0.0355 & 17 & - & - \\
\hline T3g1 & 526 & 0.52 & 0.0021 & - & - & - \\
\hline $\mathrm{T} 10$ & 680 & 0.75 & 0.0019 & 6.2 & 10.7 & 4.5 \\
\hline
\end{tabular}

${ }^{a}$ Surface area calculated by the BET method from $\mathrm{N}_{2}$ adsorption. ${ }^{b}$ Total pore volume calculated at $P / P_{0}=0.974 .{ }^{c}$ Micropore volume calculated with t-plots method from $\mathrm{N}_{2}$ adsorption. ${ }^{d}$ Pore diameter calculated by the BJH method. ${ }^{e}$ Unit cell parameter obtained from SAXS results. ${ }^{f}$ Wall thickness $=$ unit cell parameter - pore diameter.

The maximum surface area as well as pore volume occurs with $\mathrm{T} 5 \mathrm{~g} 1$, which is believed to originate from the optimal incorporation of adam-graft SQ into the silica framework. The correct order of introduction of adam-graft SQ coupled with preferred location of adam-graft SQ near the block template should lead to the structural integrity, while widening the mesopore diameter by creating pitted small pores in the vicinity of mesochannels.

For the further confirmation of the structural order, transmission electron microscopy (TEM) was employed. Representative TEM images provide additional compelling evidence of well-defined 2D-hexagonal ( $p 6 m n$ ) mesophases for both T10 and $\mathrm{T} 5 \mathrm{~g} 1$ samples, confirming the SAXS results. The primary pore size of the T10 sample is around $6.4 \mathrm{~nm}$, whereas the pore size for the T5g1 sample is around $7.5 \mathrm{~nm}$, as shown in Fig. 3(a) and (c). It is noteworthy that the mesowalls of the $\mathrm{T} 5 \mathrm{~g} 1$ sample are less smooth, as shown in Fig. 3(d), when compared with the mesowalls of the T10 sample. We speculate that the undulation

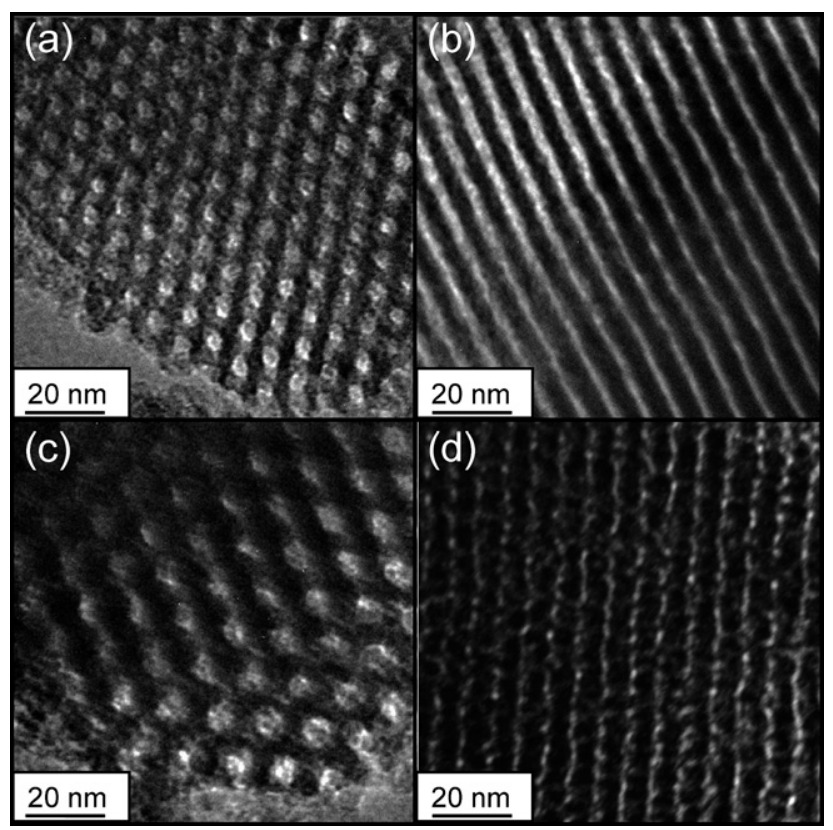

Fig. 3 Transmission electron micrographs of calcined porous silicas in the presence of a triblock Pluronic P123 template prepared with: (a) TEOS only (T10) in the [100] direction; (b) TEOS only (T10) in the [110] direction; (c) the co-condensation of TEOS and adam-graft SQ (T5g1) in the [100] direction; (d) the co-condensation of TEOS and adam-graft SQ (T5g1) in the [110] direction. of silica walls occurs at the interface between the PO blocks and silica precursors. This is due to the decrease in uniformity along the mesochannels when the adamantylphenol groups are removed, which were originally trapped between the interior silica walls.

The influence of the extent of silica condensation on mesostructural characteristics was investigated by varying the aging time of silica sols from 1 to 3 days. As shown in the SAXS patterns of Fig. 4(A) and (B), the T7g1 sample, hydrothermally treated for 1 or 2 days to extend the silicate framework, shows sharp intense peaks, but the intensity of the main $d(100)$ peak significantly decreases as the silica condensation time is further increased up to 3 days (Fig. 4(C)). It is also worth noting that a shoulder-like peak near the main reflection at larger $2 \theta$ value becomes more pronounced in the case of 3 days of aging. We believe that this does not represent a second-order reflection, but rather it represents a smaller layer spacing originating from the wall undulation mainly due to the aggregation of adamantylphenol groups as the silica condensation further progresses. As summarized in Table $\mathrm{S} 1 \dagger$, the average pore size

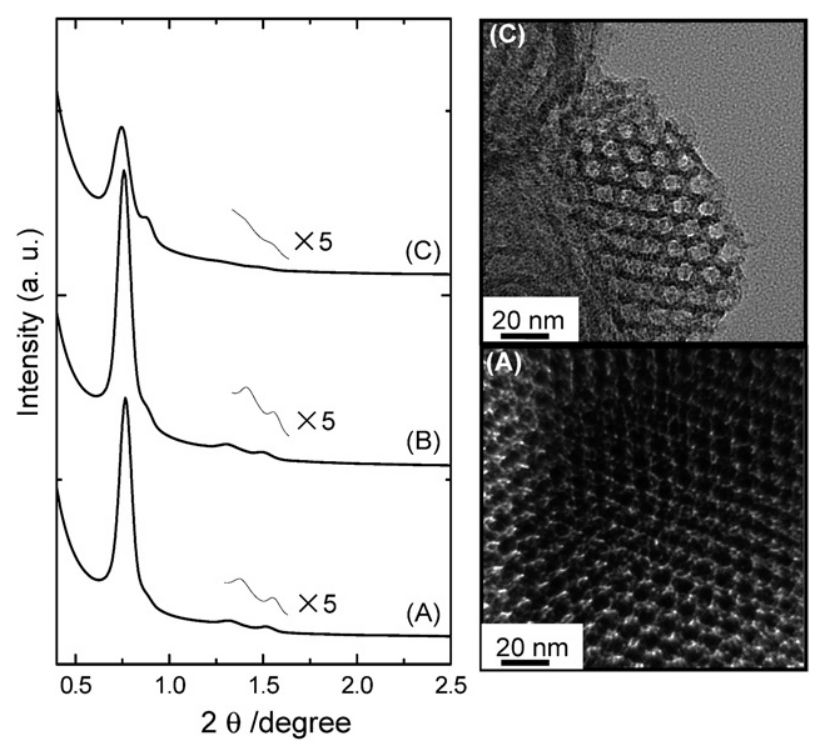

Fig. 4 Small-angle X-ray scattering patterns of different porous silicas prepared by the co-condensation of TEOS and adam-graft SQ (T7g1) at different silica gel aging times: (A) 1 day; (B) 2 days; (C) 3 days. Transmission electron micrographs of porous silicas with different periods of hydrothermal treatment ( 1 day and 3 days of aging) are also shown. 


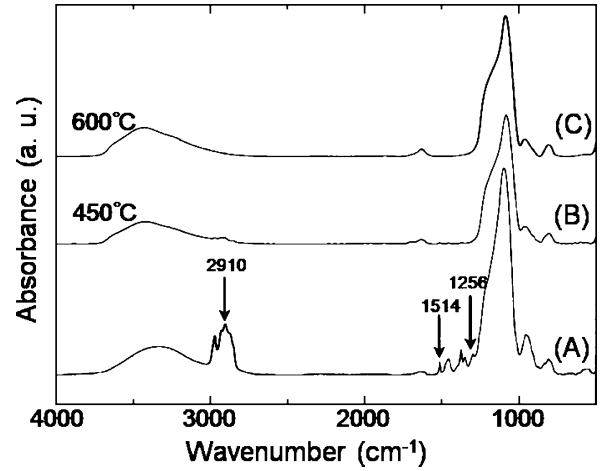

Fig. 5 The change in FT-IR spectra for porous silicas prepared with the cocondensation of TEOS and adam-graft SQ (T5g1): (A) before calcination; (B) after calcination at $450{ }^{\circ} \mathrm{C}$ under $\mathrm{N}_{2}$; (C) after calcination at $600{ }^{\circ} \mathrm{C}$ under $\mathrm{N}_{2}$.

(obtained from the adsorption branch of porous samples) increases, and its distribution becomes broader upon increasing the aging time up to 3 days. This observation is also consistent with the TEM results shown in Fig. 4.

The FT-IR spectra of mesostructured porous silica are shown in Fig. 5. The sharp bands at 1080 and $1180 \mathrm{~cm}^{-1}$ are ascribed to the $\mathrm{Si}-\mathrm{O}-\mathrm{Si}$ asymmetric stretching modes. In the case of the mesostructued silica (T5g1) before calcination (Fig. 5(A)), the $\mathrm{C}-\mathrm{H}$ stretching modes of adamantane and the $\mathrm{C}=\mathrm{C}$ stretching modes of phenyl groups appear at 2910 and $1514 \mathrm{~cm}^{-1}$, respectively. The peaks attributed to the adamantylphenol groups almost disappear after calcination at $450{ }^{\circ} \mathrm{C}$ (Fig. 5(B)), and totally disappear after $600{ }^{\circ} \mathrm{C}$ (Fig. 5(C)), indicating the decomposition of adamantylphenol moieties, which act as molecular pore generators, at the processing temperature. The decrease in the peak intensity corresponding to the phenyl ether group at $1256 \mathrm{~cm}^{-1}$ is concomitant with the decrease in peak intensities assigned to the adamantane and phenyl groups. These spectroscopic data indicate that the removal of adamantylphenol groups is mainly through the cleavage of ether bonds. Furthermore, the stretching bands around $2900 \mathrm{~cm}^{-1}$, which are related to the $\mathrm{C}-\mathrm{H}$ modes of the block copolymer template, and which also overlap with the $\mathrm{C}-\mathrm{H}$ stretching bands of adamantane, were

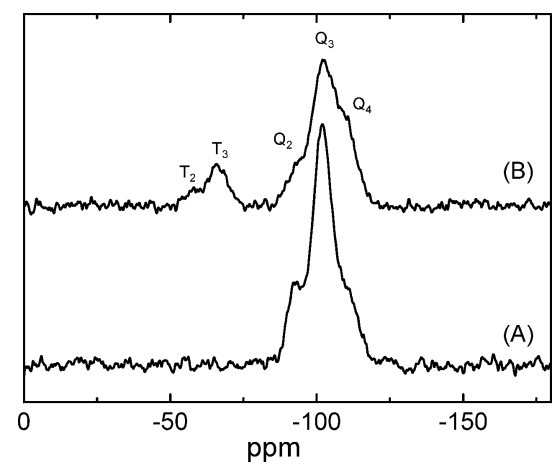

Fig. 6 Solid-state 29Si CP-MAS NMR spectra of calcined porous silicas prepared with: (A) TEOS only; (B) the co-condensation of TEOS and adam-graft SQ (T5g1). absent after calcination, confirming the complete removal of the template chains.

Fig. 6 shows the solid-state ${ }^{29} \mathrm{Si}$ CP-MAS NMR spectra of calcined $\mathrm{T} 10$ and $\mathrm{T} 5 \mathrm{~g} 1$ samples. For the mesoporous silica synthesized with TEOS only (T10), no T-resonance is observed, while characteristic $\mathrm{Q}$ resonances appear at $-110,-101$, and $-92 \mathrm{ppm}$, respectively, corresponding to $\mathrm{Q}_{4}\left(\mathrm{Si}(\mathrm{OSi})_{4}\right), \mathrm{Q}_{3}$ $\left((\mathrm{HO}) \mathrm{Si}(\mathrm{OSi})_{3}\right)$, and $\mathrm{Q}_{2}\left((\mathrm{HO})_{2} \mathrm{Si}(\mathrm{OSi})_{2}\right)$ (Fig. 6(A)). In contrast, the $\mathrm{T} 5 \mathrm{~g} 1$ mesoporous silica incorporating the adam-graft SQ represents the characteristic signals assigned to $\mathrm{CSi}(\mathrm{OSi})_{3}$ $\left(\mathrm{T}_{3}, \delta-65\right)$ and $\mathrm{CSi}(\mathrm{OSi})_{2}(\mathrm{OH})\left(\mathrm{T}_{2}, \delta-57\right)$, as shown in Fig. 6(B), confirming the presence of propyl groups inside the silica framework.

\section{Conclusion}

Highly ordered mesoporous silicas with corrugated silica walls were successfully synthesized by employing a new silica precursor containing a pore-generating carbon cage (adam-graft SQ). The lattice spacing of the mesostructure, confirmed by SAXS, increases when adam-graft SQ is first added to a solution containing the P123 block template, because the hydrophobic adamantylphenol moieties preferentially locate at the interface between the PO and the EO blocks of the block templates. The corrugated pore wall structure is confirmed by BET isotherms as well as TEM. The variation of experimental conditions such as the molar ratio between hydrophilic TEOS and hydrophobic adam-graft SQ, the order of individual precursor addition and the aging time for silica condensation, demonstrates that there is an optimum window to obtain hierarchical mesoporous structure, while refraining the coalescence of hydrophobic adamantylphenol moieties themselves during processing. The results obtained in the present study indicate that rational design of silica precursors containing pore-generating units should allow us to control the location of micropores within silica walls.

\section{Acknowledgements}

This work was financially supported by the Korea Science and Engineering Foundation (KOSEF) grant through the Acceleration Research Program (R17-2007-059-01000-0) and the NANO Systems Institute - National Core Research Center (R15-2003032-02002-0) funded by the Ministry of Education, Science and Technology (MEST) and the Brain Korea 21 Program endorsed by the MEST. Financial support from the Korean Collaborative Project for Excellence in Basic System IC Technology (System IC 2010) is also greatly acknowledged. The authors also greatly acknowledge the kind assistance of Mr Jaehan Kim at the 4C1 SAXS beamtime at the Pohang Light Source (PLS), as well as Ms Mijung Kang at the SNU National Center for Inter-University Facilities for TEM measurements.

\section{References}

1 (a) C. T. Kresge, M. E. Leonowicz, W. J. Roth, J. C. Vartuli and J. S. Beck, Nature, 1992, 359, 710; (b) S. A. Bagshaw, E. Prouzet and T. J. Pinnavaia, Science, 1995, 269, 1242; (c) A. P. Wight and M. E. Davis, Chem. Rev., 2002, 102, 3589; (d) A. Stein, Adv. Mater., 2003, 15, 763; (e) A. Sayari and S. Hamoudi, Chem. Mater., 2001, 13, 3151. 
2 (a) B. Tian, X. Liu, B. Tu, C. Yu, J. Fan, L. Wang, S. Xie G. D. Stucky and D. Zhao, Nat. Mater., 2003, 2, 159; (b) F. Schüth and W. Schmidt, Adv. Mater., 2002, 14, 629; (c) G. J. de A. A. Soler-Illia, C. Sanchez, B. Lebeau and J. Patarin, Chem. Rev., 2002, 102, 4093.

3 (a) R. Ryoo, S. H. Joo and S. Jun, J. Phys. Chem. B, 1999, 103, 7743; (b) J. Lee, S. Yoon, T. Hyeon, S. M. Oh and K. B. Kim, Chem. Commun., 1999, 2177; (c) S. H. Joo, S. J. Choi, I. Oh, J. Kwak, Z. Liu, O. Terasaki and R. Ryoo, Nature, 2001, 412, 169; $(d)$ H. I. Lee, J. H. Kim, D. J. You, J. E. Lee, J. M. Kim, W.-S. Ahn, C. Pak, S. H. Joo, H. Chang and D. Seung, Adv. Mater., 2008, 20, 757. 4 Y.-C. Hsu, Y.-T. Hsu, H.-Y. Hsu and C.-M. Yang, Chem. Mater., 2007, 19, 1120.

5 (a) P. Yang, T. Deng, D. Zhao, P. Feng, D. Pine, B. F. Chmelka, G. M. Whitesides and G. D. Stucky, Science, 1998, 282, 2244; (b) J. Sun, Z. Shan, T. Maschmeyer and M.-O. Coppens, Langmuir, 2003, 19, 8395; (c) A. Keshavaraja, V. Ramaswamy, H. S. Soni, A. V. Ramaswamy and P. Ratnasamy, J. Catal., 1995, 157, 501; (d) D. Zhao, P. Yang, B. F. Chmelka and G. D. Stucky, Chem. Mater. $1999,11,1174$

6 (a) C.-G. Oh, Y. Baek and S.-K. Ihm, Adv. Mater., 2005, 17, 270; (b) M. Antonietti, B. Berton, C. Göltner and H.-P. Hentze, Adv. Mater. 1998, 10, 154; (c) B. T. Holland, L. Abrams and A. Stein, J. Am. Chem. Soc., 1999, 121, 4308; (d) B. Lebeau, C. E. Fowler, S. Mann, C. Farcet, B. Charleux and C. Sanchez, J. Mater. Chem., 2000, 10, 2105; (e) B. Z hang, S. A. Davis and S. Mann, Chem. Mater., 2002, 14, 1369.

7 (a) B. T. Holland, C. F. Blanford and A. Stein, Science, 1998, 281, 538; (b) A. Imhof and D. J. Pine, Nature, 1997, 389, 948; (c) C. Jacobsen, C. Madsen, J. Houzvicka, I. Schmidt and A. Carlsson, J. Am. Chem. Soc., 2000, 122, 7116.

8 J. Sun, Z. Shan, T. Maschmeyer, J. Moulijn and M.-O. Coppens, Chem. Commun., 2001, 2670.

9 P. Van Der Voort, P. I. Ravikovitch, K. P. De Jong, A. V. Neimark, A. H. Janssen, M. Benjelloun, E. Van Bavel, P. Cool, B. M. Weckhuysen and E. F. Vansant, Chem. Commun., 2002, 1010. 10 K. Miyazawa and S. Inagaki, Chem. Commun., 2000, 2121.

11 Y. Long, T. Xu, Y. Sun and W. Dong, Langmuir, 1998, 14, 6173.

12 W. W. Lukens Jr, P. S- Winkel, D. Zhao, J. Feng and G. D. Stucky, Langmuir, 1999, 15, 5403

13 M. Kruk, M. Jaroniec, C. H. Ko and R. Ryoo, Chem. Mater., 2000 12, 1961

14 M. Choi, H. S. Cho, R. Srivastava, C. Venkatesan, D.-H. Choi and R. Ryoo, Nat. Mater., 2006, 5, 718.

15 (a) Y. Kang, H. I. Lee, Y. Zhang, Y. Han, J. Yie, G. D. Stucky and J. M. Kim, Chem. Commun., 2004, 1524; (b) D. Margolese,
J. A. Melero, S. C. Christiansen, B. F. Chmelka and G. D. Stucky, Chem. Mater., 2000, 12, 2448; (c) J. A. Melero, G. D. Stucky, R. Van Grieken and G. Morales, J. Mater. Chem., 2002, 12, 1664; (d) S. L. Burkett, S. D. Sims and S. Mann, Chem. Commun., 1996, 1367.

16 B. J. Cha, S. Kim, J.-K. Lee, D. Y. Yoon, H.-W. Rhee and K. Char, Chem. Mater., 2006, 18, 378

17 B. J. Cha, S. Kim and K. Char, Macromol. Res., 2005, 13, 176.

18 D. Zhao, Q. Huo, J. Feng, B. F. Chmelka and G. D. Stucky, J. Am. Chem. Soc., 1998, 120, 6024

19 J. M. Kim and G. D. Stucky, Chem. Commun., 2000, 1159.

20 D. Zhao, J. Feng, Q. Huo, N. Melosh, G. H. Fredrickson, B. F. Chmelka and G. D. Stucky, Science, 1998, 279, 548.

21 Q. Huo, D. I. Margolese, U. Ciesia, P. Feng, T. E. Gier, P. Sieger, R. Leon, P. M. Petroff, F. Schüth and G. D. Stucky, Nature, 1994, 368, 317 .

22 Q. Huo, D. I. Margolese, U. Ciesia, D. G. Demuth, P. Feng, T. E. Gier, P. Sieger, A. Firouzi, B. F. Chmelka, F. Schüth and G. D. Stucky, Chem. Mater., 1994, 6, 1176.

23 M. Kruk and M. Jaroniec, Chem. Mater., 2001, 13, 3169.

24 J. R. Matos, L. P. Mercuri, M. Kruk and M. Jaroniec, Langmuir, $2002, \mathbf{1 8}, 884$.

25 P. I. Ravikovitch and A. V. Neimark, Langmuir, 2002, 18, 1550.

26 M. Kruk, M. Jaroniec, S. Joo and R. Ryoo, J. Phys. Chem. B, 2003, 107, 2205.

27 P. C. Ball and R. Evans, Langmuir, 1989, 13, 714.

28 P. Van Der Voort, P. I. Ravikovitch, K. P. De Jong, M. Benjelloun, E. Van Bavel, A. H. Janssen, A. V. Neimark, B. M. Weckhuysen and E. F. Vansant, J. Phys. Chem. B, 2002, 106, 5873 .

29 (a) Z. Y. Yuan, J. L. Blin and B. L. Su, Chem. Commun., 2002, 504; (b) S. A. Bagshaw, Chem. Commun., 1999, 1785; (c) S. A. Bagshaw, J. Mater. Chem., 2001, 11, 831 .

30 M. Kruk, M. Jaroniec and A. Sayari, Langmuir, 1997, 13, 6267.

31 V.-T. Hoang, Q. Huang, M. Eić, T.-O. Do and S. Kaliaguine, Langmuir, 2005, 21, 2051.

32 N. Hüsing, C. Raab, V. Torma, A. Roig and H. Peterlik, Chem. Mater., 2003, 15, 2690.

33 D. Brandhuber, V. Torma, C. Raab, H. Peterlik, A. Kulak and N. Hüsing, Chem. Mater., 2005, 17, 4262.

34 D. Brandhuber, H. Peterlik and N. Hüsing, J. Mater. Chem., 2005, 15, 3896.

35 T. Amatani, K. Nakanishi, K. Hirao and T. Kodaira, Chem. Mater., $2005,17,2114$.

36 L. Huerta, C. Guillem, J. Latorre, A. Beltrán, D. Beltrán and P. Amorós, Chem. Commun., 2003, 1448. 